\title{
Biological, Programmatic and Sociopolitical Dimensions of Child Undernutrition in Three States in India
}

\author{
Purnima Menon, Katharina Raabe and Anjor Bhaskar
}

\begin{abstract}
The recently developed India State Hunger Index 2008 highlights the continuing sorry state of hunger in India, and shows that children underweight makes the largest contribution to hunger index scores for most of India. In this article, we apply an assessment framework developed by the Mainstreaming Nutrition Initiative to understand three dimensions of child undernutrition in India: (1) the biological/ epidemiological aspects of the nutrition situation, (2) the programmatic interventions and environment and (3) the sociopolitical environment for nutrition. We conduct this assessment for three states in India, each of which offers a distinct typology: (a) Bihar, an extremely poor northern state with high levels of undernutrition; (b) Karnataka, a southern state with high economic growth, but high child undernutrition rates; (c) Tamil Nadu, a southern state portrayed as an example of successful health and nutrition programming, but with rates of undernutrition that are still very high.
\end{abstract}

\section{Introduction}

The recently developed India State Hunger Index 2008 (Menon et al. 2008b) and other analyses (Deaton and Drèze 2009) highlight the continuing sorry state of hunger in India. Despite concern among policymakers, effective solutions have been slow to emerge even although lessons abound from other countries (von Braun et al. 2008) and within India (Dubowitz et al. 2007; Baqui et al. 2008).

Recent literature in health policy and nutrition (Shiffman 2007; Shiffman and Smith 2007; Bryce et al. 2008) suggests that solutions for public health problems have not been adopted at the needed scale and intensity because of competing priorities, and a lack of consensus and clarity among key stakeholders. In India, as elsewhere, progress is affected by divergent perspectives within the nutrition community and added imperatives from legal interventions. Divergent perspectives often arise because diagnoses of the problem, and subsequent solutions, are seen from specific points of view rather than a more encompassing view (Pelletier 2001).
In this article, we apply an assessment framework developed by the Mainstreaming Nutrition Initiative (Menon et al. under review) to understand undernutrition in three states in India - Bihar, Karnataka and Tamil Nadu. The assessment framework enables a comprehensive analysis of three distinct, but interrelated dimensions of the nutrition problem: (1) the biological/epidemiological aspects of the nutrition situation, (2) the programmatic interventions and environment and (3) the sociopolitical environment for nutrition. This framework recognises and stresses that the domains are interlinked. It also suggests that the sociopolitical domain often underlies the other two domains by influencing not just how nutrition problems and proposed solutions to those problems are framed and perceived (Kingdon 1995), but also how policy development and implementation is perceived and acted upon in a given context.

India's major policy response to undernutrition, the Integrated Child Development Services 
Table 1 Changes in stunting and wasting between 1998-9 and 2005-06

\begin{tabular}{lll}
\hline & \% Stunted & \% Wasted \\
\hline Bihar NFHS-2 (1998-99) & 58.4 & 25.4 \\
Bihar NFHS-3 (2005-06) & 50.1 & 32.6 \\
Karnataka NFHS-2 (1998-99) & 41.9 & 25.1 \\
Karnataka NFHS-3 (2005-06) & 42.4 & 18.9 \\
Tamil Nadu NFHS-2 (1998-99) & 35.2 & 22.5 \\
Tamil Nadu NFHS-3 (2005-06) & 31.1 & 22.9 \\
\hline
\end{tabular}

Source NFHS-II and NFHS-III data.

(ICDS) programme, is possibly the largest nutrition initiative in the world. It seeks to provide an integrated set of services to preschool children (below 6 years), pregnant women and nursing mothers, and has a current budget close to US\$1.5 billion per year. The programme is implemented through village-based childcare centres, referred to as anganwadis, which are run by community volunteers who receive a modest remuneration. The programme's goals are ambitious, but its effectiveness at addressing undernutrition has been constrained due to a variety of factors relating to design, implementation and governance, among others (Gragnolati et al. 2005). Given the investments in the ICDS programme as a platform for

Figure 1 Co-occurrence of stunting and wasting (NFHS-III, 2005-06)

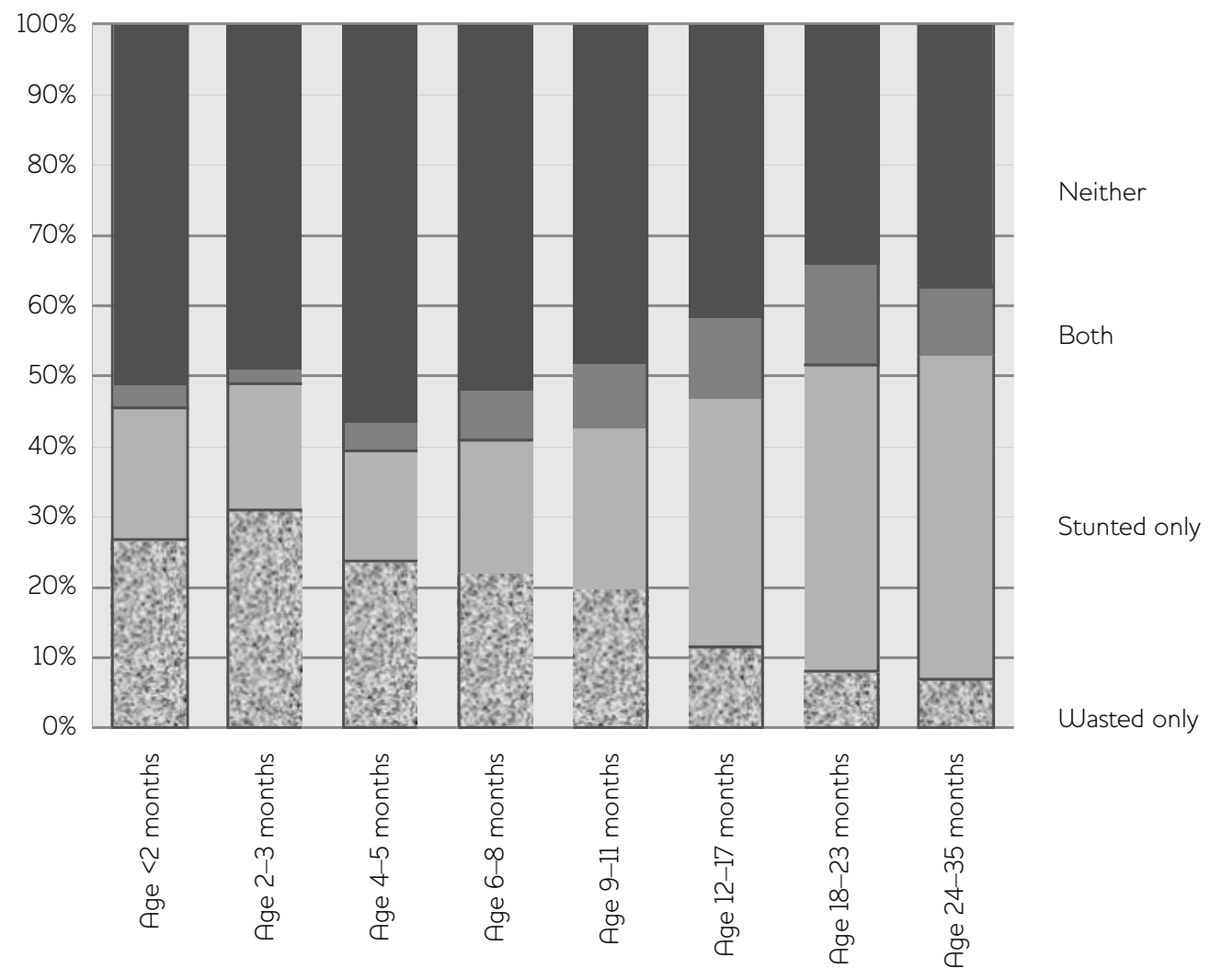

Source Authors' calculations using data from the National Family Health Survey-III (NFHS-III) from 2005-06. 
addressing undernutrition, we focus much of our analysis on this programme.

\section{Patterns of undernutrition in India and the three states}

Since stunting and wasting are distinct manifestations of undernutrition, while underweight is non-specific, we focus our analysis on stunting and wasting. The NFHS-II and NFHSIII data (Table 1) shows that although stunting rates declined in Bihar between 1998-9 and 2005-06, they remained largely static in Karnataka, and decreased somewhat less in Tamil Nadu than in Bihar. Over the same period, wasting increased in Bihar, decreased substantially in Karnataka and did not change in Tamil Nadu. An initial empirical analysis of preliminary NFHS-III data (Nair 2007) suggests that variability in trends across states is explained largely by maternal age and early breast-feeding, but does not explore other programmatic or policy reasons.

The NFHS-III report shows that stunting and underweight increase rapidly in the first two years of life, while wasting remains largely constant. Stunting among children 18-24 months of age is almost triple the rate of stunting among infants $0-3$ months of age, indicating a large postnatal contribution to stunting. Here, we analyse the co-occurrence of stunting and wasting in the same child, and find that stunting and wasting do not overlap greatly in terms of absolute prevalence (Figure 1) but that the cooccurrence also increases between birth and two years of age. The proportion of children neither stunted nor wasted declines over the first two years of life, such that among children 24-36 months of age, only about one-third of children are neither stunted nor wasted.

Taken together, this indicates that (1) intervention is needed in the first two years of life for the prevention of both stunting and wasting, and rehabilitation of severely wasted children; (2) interventions (likely maternal nutrition and low birth weight prevention) are needed to address very early wasting and stunting; (3) actions for preventing stunting might differ from those to manage the burden of wasting, particularly severe wasting.

\section{Biological factors}

We examine the immediate determinants of undernutrition using data from the third round of the National Family Health Survey (NFHS-III) dataset (IIPS and Macro International 2007). Based on the current understanding of the drivers of poor nutrition among young children (Black et al. 2008; World Bank 2006), we focus our analysis on diet quality, childhood illness and care-seeking for childhood illnesses among children under the age of 2 years (UNICEF 1990; Engle et al. 1999). An investigation of maternal undernutrition is outside the scope of this article.

Table 2 presents an overview of the major known determinants of child undernutrition (UNICEF 1990; Engle et al. 1999), focusing on determinants of (1) nutrition at birth, (2) nutrient intake among young children and

(3) prevention and care of illness among young children. We also highlight some indirect determinants of child undernutrition.

\subsection{Direct determinants of nutrition}

Nutrition at birth: In developing countries, nutrition at birth is influenced by maternal nutrition, use of antenatal care, age at conception and other factors. These indicators are worst off in Bihar with high levels of low maternal body mass index (BMI) and maternal anaemia, as well as low coverage and use of antenatal care. Antenatal care coverage is excellent in Tamil Nadu, reflecting the priority given to primary healthcare.

Nutrient intake: Given the association between early child-feeding practices and the nutrient adequacy of children's diets (Arimond et al. 2008; Mourad et al. 2008; WHO 2008), poor feeding practices are a major barrier to improved nutrition in India. Infant-feeding practices other than the consumption of sources of dairy in early childhood are poor in all three states, including abysmally low consumption of iron-rich foods, low frequency of feeding and low diet diversity.

Prevention and care of illness: Prevention and care for common childhood illnesses vary widely across the three states, with higher rates of immunisation, safe stool disposal and appropriate care during diarrhoea in Tamil Nadu and Karnataka compared with Bihar. That these indicators are still poor in well-performing states like Tamil Nadu, however, suggests that illness prevention and appropriate care are important for improving nutrition. 


\begin{tabular}{|c|c|c|c|c|}
\hline Indicators & India (\%) & Bihar (\%) & Karnataka (\%) & T. Nadu (\%) \\
\hline \multicolumn{5}{|l|}{ Child undernutrition } \\
\hline Stunting & 48.0 & 55.6 & 42.4 & 30.9 \\
\hline Underweight & 42.5 & 55.9 & 33.3 & 29.8 \\
\hline Wasting & 19.8 & 27.1 & 18.9 & 22.2 \\
\hline Child anaemia (children 6-59 months of age) & 69.5 & 78.0 & 70.4 & 64.2 \\
\hline Low birth weight (for children with reported birth weights) & 21.5 & 27.6 & 18.7 & 17.2 \\
\hline \multicolumn{5}{|l|}{ Maternal undernutrition } \\
\hline Maternal anaemia (any anemia) & 55.3 & 67.4 & 51.5 & 53.2 \\
\hline Maternal low BMI $(<18.5)$ & 35.6 & 45.1 & 35.5 & 28.4 \\
\hline Maternal low height $(<145 \mathrm{~cm})$ & 11.4 & 15.9 & 9.9 & 9.5 \\
\hline$>3$ antenatal visits & 52.0 & 17.0 & 79.5 & 95.9 \\
\hline \multicolumn{5}{|l|}{ Breast-feeding } \\
\hline Median duration of exclusive breast-feeding (months) & 2.0 & 0.7 & 3.1 & 1.1 \\
\hline Children exclusively breast-fed at 2-3 months of age & 50.9 & 35.2 & 61.1 & 39.7 \\
\hline Children exclusively breast-fed at $4-5$ months of age & 27.6 & 7.6 & 41.3 & 19.2 \\
\hline \multicolumn{5}{|l|}{ Complementary feeding and diet quality } \\
\hline $\begin{array}{l}\text { All 6-23-month-old children receiving breast milk, milk or } \\
\text { milk products }\end{array}$ & 97.6 & 97.9 & 96.1 & 95.4 \\
\hline $\begin{array}{l}\text { All 6-23-month-old children who were fed appropriate } \\
\text { number of food groups }\end{array}$ & 35.3 & 33.6 & 43.7 & 46.2 \\
\hline $\begin{array}{l}\text { All 6-23-month-old children fed the minimum number of } \\
\text { times per day }\end{array}$ & 41.5 & 53.5 & 42.9 & 53.1 \\
\hline Iron rich foods (children 6-35 months) & 14.6 & 6.4 & 19.8 & 32.8 \\
\hline Vitamin A rich foods (children 6-35 months) & 47.1 & 51.1 & 53.1 & 63.1 \\
\hline \multicolumn{5}{|l|}{ Hygiene and illness among children } \\
\hline Children with diarrhoea (for children under 2) & 14.1 & 15.2 & 15.0 & 9.5 \\
\hline $\begin{array}{l}\text { Diarrhoea treated with ORT or increased fluids (for children } \\
\text { under } 2)^{1}\end{array}$ & 40.6 & 43.9 & 49.6 & 50.5 \\
\hline Children's last stools disposed of safely² (for children under 2) & 25.4 & 13.8 & 25.2 & 21.1 \\
\hline \multicolumn{5}{|l|}{ Underlying determinants } \\
\hline Maternal literacy ${ }^{3}$ & 55.1 & 37.0 & 59.7 & 69.4 \\
\hline No say over four decisions (own healthcare, major purchases, & 205 & 272 & 269 & 82 \\
\hline $\begin{array}{l}\text { Calorie deficiency }(<1,632 \mathrm{kcal} \text {, as used in India State Hunger } \\
\text { Index) }\end{array}$ & 20.0 & 17.3 & 28.1 & 29.1 \\
\hline $\begin{array}{l}\text { Average year on year \% change in GSDP for the } 6 \text {-year } \\
\text { period }(2000-6)^{*}\end{array}$ & 6.6 & 5 & 5.9 & 5.1 \\
\hline $\begin{array}{l}\text { Per capita Net State Domestic Product (NSDP) at Current } \\
\text { Prices (New Series: 1999-2000) In India - Part I (2005-6, } \\
\text { year in which the NFHS III survey was conducted) }{ }^{4 * *}\end{array}$ & 25,956 & 7,875 & 27,101 & 29,958 \\
\hline Growth Rate of per capita NSDP (State Income): at 1993-4 & 6.1 & 11.1 & 9.4 & 7.9 \\
\hline Prices in India (Year 2004-05) (\% Growth over previous year) ${ }^{5 *}$ & & & & \\
\hline
\end{tabular}

Data sources NFHS-III Report, 2007; India State Hunger Index (2008); *National Accounts Statistics, CSO, Gross state domestic product (at factor cost) in 1999-2000 prices (latest price series); ${ }^{* *}$ Central Statistical Organisation; ***Ministry of Agriculture, Government of India

1 Among Children under age 5 who had diarrhoea in the two weeks preceding the survey, percentage who received oral rehydration therapy (ORT) or increased fluids. 2 For all children less than 24 months of age (includes children with higher birth indices as well and not just the youngest child). 3 Literacy rate among women age 15-49 in each state. 4 Position as on 28 February 2008. 5 Position as on 21 July 2006. 


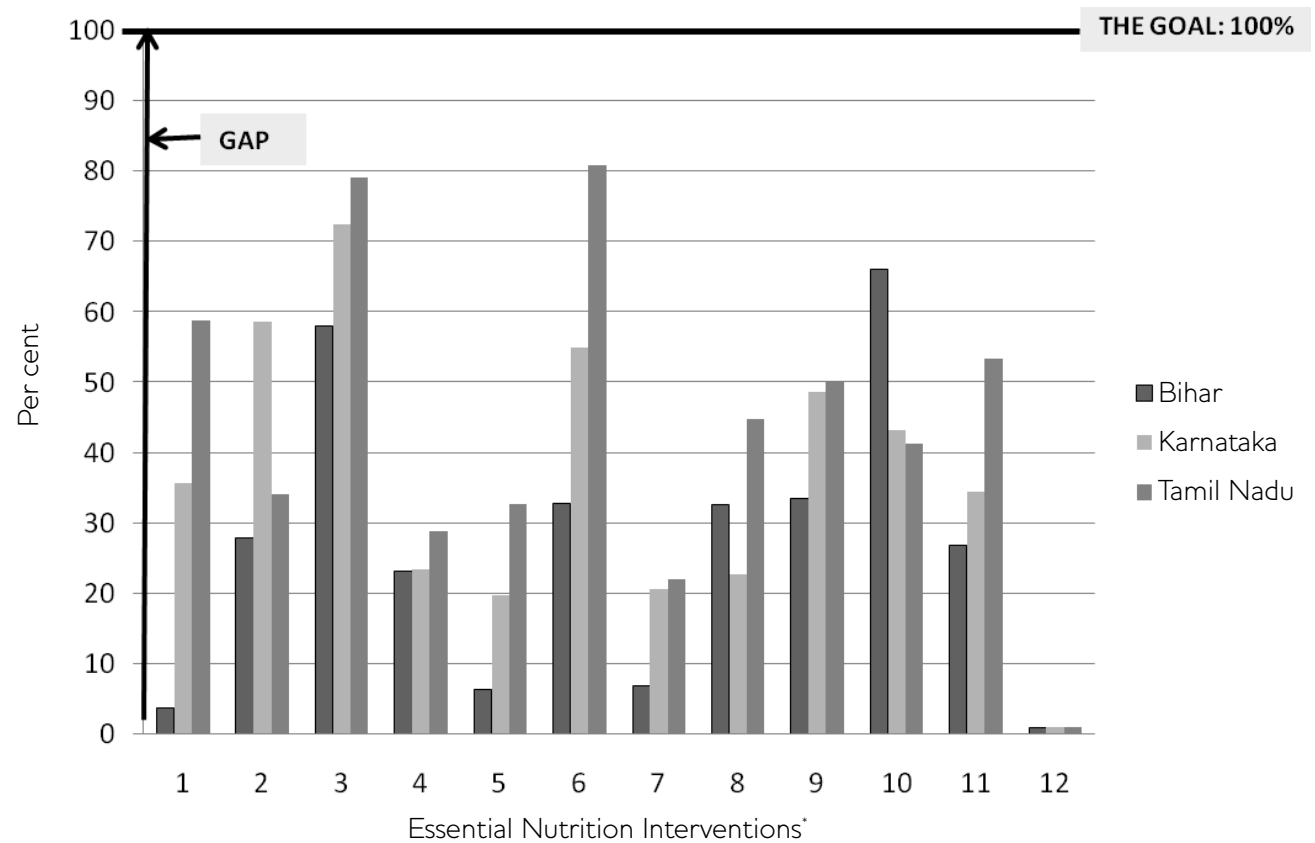

*Essential Nutrition Interventions include : 1 Early initiation of breastfeeding. 2 Exclusive BF (0-6 months).

3 Introduction of complementary foods at 6-9 months. 4 Three expected IYCF practices (source of dairy, minimum meal frequency, minimum number of food groups). 5 Iron-rich foods. 6 All basic immunisations.

7 Stools safely disposed. 8 Vitamin A supplementation (<3 years of age). 9 Adolescent girls (15-19 years) non-anaemic. 10 Household has adequately iodised salt. 11 Diarrhoea: children fed more than or about the same as usual.

12 Severe acute malnutrition: children with access to appropriate care.

Source Authors' estimates using NFHS-III data.

\subsection{Indirect determinants of nutrition}

Even though per capita calorie deficiency levels are higher in Tamil Nadu and Karnataka than in Bihar (Menon et al. 2008a), indicators like maternal literacy and poverty rates are the worst in Bihar. Women's status as proxied by their control over decisions are known to be associated with child nutrition (Smith et al. 2003). These are lower than the all India average in Bihar and Karnataka, but much better than average in Tamil Nadu. These indirect determinants of undernutrition need policy attention because they influence undernutrition by increasing the ability of caregivers to demand, access and make use of health, nutrition and other services.

\section{Programmatic factors}

The status of inputs to reduce undernutrition is examined using the NFHS-III data, guided by recommendations for evidence-based nutrition interventions in Bhutta et al. (2008), as well as those of an Expert Task Force on Children Under Two, a task force of the Coalition for Sustainable Nutrition Security of India. ${ }^{2}$

\subsection{ICDS intervention choice is weak}

From a design perspective, current intervention packages designed within the ICDS programme and the National Rural Health Mission (NRHM) are not adequately focused on specific nutrition outcomes even though they cover the right age range (i.e. adolescence through to early childhood) and seek to provide an integrated set of services across this age range. The specific interventions within these programme packages do not include known effective interventions such as high quality age-appropriate counselling to support infant feeding, provision of micronutrient supplements or other means of improving the diets of young infants. In addition, there is not adequate convergence with other sectors to ensure the provision of other inputs 


\begin{tabular}{|c|c|c|c|c|}
\hline Indicators & India (\%) & Bihar (\%) & Karnataka (\%) & T. Nadu (\%) \\
\hline \multicolumn{5}{|l|}{ ICDS coverage and use (all children) } \\
\hline $\begin{array}{l}\text { Children }<6 \text { years who live in a survey area covered by } \\
\text { an AWC }\end{array}$ & 81.1 & 87.9 & 92.9 & 97.0 \\
\hline $\begin{array}{l}\text { Children }<6 \text { years who had received any service from an } \\
\text { AWC in past year }\end{array}$ & 28.4 & 8.8 & 33.5 & 41.6 \\
\hline Children $<6$ years who received supplementary food & 26.3 & 4.2 & 28.0 & 32.2 \\
\hline Children $<6$ years who received immunisations at an AWC & 20.0 & 7.7 & 26.2 & 33.7 \\
\hline Children $<6$ years who received health check-up at an AWC & 15.8 & 0.8 & 17.1 & 25.5 \\
\hline Children $<6$ years who were weighed at an AWC & 18.2 & 0.7 & 17.8 & 31.6 \\
\hline Children $<6$ years weighed whose caregivers were counselled & 48.9 & - & 52.5 & 75.7 \\
\hline \multicolumn{5}{|l|}{ ICDS coverage and use among lowest standard of living quintile } \\
\hline $\begin{array}{l}\text { Children }<6 \text { years who live in a survey area covered by } \\
\text { an AWC }\end{array}$ & 88.3 & 94.5 & 93.7 & 98.3 \\
\hline $\begin{array}{l}\text { Children }<6 \text { years who had received any service from an } \\
\text { AWC in past year }\end{array}$ & 34.7 & 10.9 & 38.6 & 47.7 \\
\hline $\begin{array}{l}\text { Funds allocated by the Central government for ICDS used } \\
\text { in 2005-6* }\end{array}$ & - & 54.6 & 115.8 & 161.5 \\
\hline
\end{tabular}

*Percentages greater than $100 \%$ indicate allocations from the state government in addition to those from the central government.

Source Seventh Report of the Supreme Court Commissioners of India on the Right to Food Act (2007).

such as health care and water and sanitation to reduce undernutrition.

The predominant reliance on the ICDS programme platform with its strong food focus, has caused the debate on intervention choices to be highly focused on supplementary feeding. Debates on the use of packaged foods versus hot cooked meals, have often deflected attention from other critical gaps, i.e. the lack of emphasis on building awareness and support for infant feeding, ensuring the nutritional adequacy of children's diets, and access to water and sanitation and preventive healthcare.

\subsection{ICDS implementation is weak}

Figure 2 shows the status of basic inputs for reducing childhood undernutrition for India and for our three focus states. Nationwide coverage for all inputs is less than 50 per cent, and is even lower for inputs that relate to the adequacy of diets and hygiene practices. The status of almost all inputs is better in Tamil Nadu but large gaps remain even there. The most salient challenges for all three states include exclusive breastfeeding and ensuring the quality of child diets and hygiene practices. Karnataka and Tamil Nadu have achieved high immunisation coverage, but vitamin A coverage and consumption of iodised salt are still low. Bihar, on the other hand has low coverage of even basic health services. In all states, over 50 per cent of adolescent girls are anaemic, increasing the likelihood that they will enter marriage and pregnancy with compromised nutritional status.

Although the availability of Anganwadi centres across the country is high, utilisation of services is very low; this is seen even in the lowest standard of living quintile (Table 3 ). The greater coverage of services in Tamil Nadu can provide operational lessons on service provision and convergence between ICDS and health sector programmes. However, the relatively low usage of ICDS services even among the poorest in Tamil Nadu as well as Bihar and Karnataka points to the need to fully understand the demand-side constraints.

\section{Sociopolitical/governance factors}

In this section we assess governance challenges related to the supply and demand side, using data from a 2008/09 governance study in Karnataka and Bihar by IFPRI, the Institute for Social and Economic Change, and the Tata Institute of Social Sciences. In Bihar, qualitative case studies were conducted in Madhubani and Nalanda 
districts, using process-mapping techniques. In Karnataka, a survey of 51 anganwadi workers was conducted in 12 districts, randomly drawn from each of Karnataka's 12 divisions. For Tamil Nadu, we draw on the literature on the ICDS programme and health services.

\subsection{Supply-side components and reform initiatives}

We explore the following supply side components: (1) the institutional structure of service provision; (2) the management and financing of service provision; and (3) the training and capacity development of ICDS functionaries.

\section{Institutional structures and recruitment}

India has a three-tier structure of local government, consisting of Gram Panchayats (village clusters), blocks and districts. In order to improve the availability of ICDS services, the ICDS programme engages structures at all three tiers. At the core of the programme are childcare centres at the village level, each being headed by one anganwadi worker and supported by one anganwadi helper. Given the provisions of the 73rd Constitutional Amendment, responsibilities for the appointment and supervision of the anganwadi workers rest with the Gram Panchayats. However, among the three states, only Bihar has transferred the respective authority of anganwadi workers' selection and remuneration to the Gram Panchayats. The case study from Bihar indicates that the delegation of powers of selection of anganwadi workers and helpers to the Gram Panchayat is, however, not necessarily enforced, mainly because of a centralised and administratively complex system, the lack of technical and managerial expertise of management at all administrative levels, and village class and caste conflicts. The main responsibility for the ICDS services and the supervision of anganwadi services therefore rests with the staff members at the block level, i.e. the CDPO and the lady supervisor. As government restrictions on the employment of public officials preclude the filling of the sanctioned posts of supervisors and CDPOs, training, monitoring and supervision of anganwadi workers is sub-optimal.

\section{Institutional structures and financing}

The provision and financing of ICDS services varies tremendously across the three states (Table 3), with higher financing for nutrition programmes from state funds in Tamil Nadu (Seshadri 2003), and underutilisation of central funds in Bihar (Supreme Court Commissioners' Report 2007).
The provision and financing is influenced by a number of governance challenges, including:

- Complex and time-consuming procurement and administrative procedures

- Inadequate ICT capacity

- Inadequate work environments and low recruitment of anganwadi workers

- Inadequate knowledge and skill base of anganwadi workers and lower-level functionaries due to ineffective and irregular institutional and/or community-based training and the absence of in-service training

- Insufficient learning, supportive mentoring, monitoring and supervision also due to transfer- and tenure-related high turnover rates of (high-level) ICDS officials.

These governance problems preclude the convergence of the anganwadi centres with health and education services at the village level; limit the integration of Gram Panchayats, NGOs, and other civil society groups; and consequently constrain ICDS service delivery in terms of quality, availability, beneficiary targeting and resource utilisation at all administrative levels (see, e.g. Dubowitz et al. 2007; Gragnolati et al. 2005; GoI 2006a). Additional challenges to the decentralisation of the planning and design of ICDS services refer to the limited capacity of the district level staff to adequately assess and plan locally specific modifications to the core ICDS programme and to elicit support from communities (Seshadri 2003).

The achievements of Tamil Nadu's nutrition efforts to improve scale and quality of services are recognised; however earlier efforts were not fully sustained due to later changes in operational design and management (Heaver 2002). New challenges for Tamil Nadu include ensuring a preventive focus, increasing access, sustaining staff motivation and increasing demand for services (Rajivan 2006). In spite of a long history of movements addressing castebased equity, implementing feeding programmes and improving health services, recent studies also suggest that women's status and male alcohol consumption are significant barriers in Tamil Nadu (Sridhar 2008; Harriss-White 2004).

\subsection{Demand-side components and reform initiatives}

The governance challenges in ICDS programme implementation are recognised by the GoI in 
current reforms to the ICDS implementation framework and other policy actors. These attribute the limited effectiveness of the ICDS programme to the predominantly supply-side driven mode of programme implementation (GoI 2007) but also aim to strengthen the demand side. Recent demand-side initiatives seek to make community members more aware about their entitlements and involve them in programme implementation to create a sense of ownership. Means of community mobilisation involve the creation of mothers' committees to supervise the anganwadi workers and help in food procurement, or local women self-help groups in the procurement and preparation of food. However, the Bihar case study indicates that these mechanisms are not necessarily implemented in practice, partly because of the limited mobilisation of women self-help groups in the state or unawareness of mothers' committee members regarding the committee's role.

Case study evidence suggests that where anganwadi workers come from 'well-connected' families, complaints by community members, for example about absenteeism, have little effect. In order to solve problems related to local elite capture and to promote the role of communities and that of community-based monitoring, anganwadi workers could be appointed through communities or Gram Panchayats rather than through the state government. As indicated above, Bihar has made considerable efforts in this regard. However, the field evidence suggests that caste politics can easily limit the effectiveness of this approach. Similarly, the Right to Food Campaign (2008) also warns that community appointments may not address all caste-, class-, and gender-based needs within diverse communities.

In addition to the direct appointments, the accountability of anganwadi workers could be strengthened by making anganwadi workers accountable to all programme users/beneficiaries for the outcomes of the ICDS programme interventions. This would require ICDS interventions to move away from being input- to being result-oriented. In the presence of effective community participation, this could also involve the introduction of performance-based remuneration systems for anganwadi workers. Again, the effectiveness of such a scheme would require behavioural changes of community members regarding caste, gender, and the social position of anganwadi workers.
The UNICEF Dular programme in Bihar attempted to change these aspects by training local volunteers as local health resource workers (LHRW) to (1) link the community and the ICDS system through a life-cycle approach to the health of women and children; (2) promote appropriate health, nutrition and childcare practices through interpersonal communication; and (3) educate families (Dubowitz et al. 2007). An evaluation of the programme suggested that UNICEF's facilitating role helped address operational bottlenecks, while the LHRW's were crucial in creating community ownership, awareness about services and accountability while working within existing systems.

\section{Conclusions}

We come to four main conclusions:

1 Evidence-based nutrition, health and water/sanitation services need to better align and converge around the critical age window from pre-pregnancy to early childhood. For all three states, a major challenge is addressing feeding and care of young children to improve diet quality, hygiene and reduce illness burdens.

2 Increasing coverage and utilisation of the services in the ICDS, health and water/sanitation is essential. All are necessary to improve nutrition; scaling up ICDS alone will not be adequate.

3 Governance challenges to improve the quality of services need immediate attention. Although these challenges are greater in some states than in others, they cannot be ignored in the efforts to achieve greater coverage, ensure quality, and assure convergence.

4 Developing mechanisms for increasing the demand for services, and hence improving utilisation rates is critical. Doing this requires addressing inequities by caste and gender.

Although we do not make state-specific recommendations, our analysis highlights the considerable state-to-state variability in the patterns and the determinants of undernutrition, as well as implementation characteristics and the nature of governance challenges. This needs to be explicitly recognised in developing guidelines and in evaluating the impact of policy reforms. 


\section{Notes}

* We thank Regina Birner (IFPRI) for her thoughtful and constructive comments. We greatly acknowledge her contribution and the contributions of Gayathridevi (Institute for Social and Economic Change) and Madhushree Sekher (Tata Institute of Social Sciences) to the case studies in Bihar and the survey evidence in Karnataka. Funding for the fieldwork in Bihar and Karnataka was provided by the Bank of Netherlands Partnership Program (BNPP) Trust Fund of the World Bank for the project, 'Gender and Governance in Rural Services'.

1 A multivariate regression analysis of these determinants is outside the scope of this article, but is planned as future research.

\section{References}

Arimond, M.; Daelmans, B. and Dewey, K. (2008) 'Indicators for Feeding Practices in Children', Lancet 37 1.9612: 541-42, http://dx.doi.org/ 10.1016/S0140-6736(08)60250-0 (accessed 15 May 2009)

Baqui, A.H.; Rosecrans, A.K.; Williams, E.K.; Agrawal, P.K.; Ahmed, S.; Darmstadt, G.L.; Kumar, V.; Kiran, U.; Panwar, D.; Ahuja, R.C.; Srivastava, V.K.; Black, R.E. and Santosham, M. (2008) 'NGO Facilitation of a Government Community-based Maternal and Neonatal Health Programme in Rural India: Improvements in Equity', Health Policy and Planning 23.4: 234-43, http://dx.doi.org/10.1016/ S0140-6736(08)60250-0 (accessed 15 May 2009)

Bhutta, Z.A.; Ahmed, T.; Black, R.E.; Cousens, S.; Dewey, K.; Giugliani, E.; Haider, B.A.; Kirkwood, B.; Morris, S.S.; Sachdev, H.P.S. and Shekar, M. for the Maternal and Child Undernutrition Study Group (2008) What Works? Interventions for Maternal and Child Undernutrition and Survival, published online 17 January, http://dx.doi.org/ 10.1016/S01406736(08)60250-0 (accessed 15 May 2009)

Black, R.E.; Allen, L.H.; Bhutta, Z.A.; Caulfield, L.E.; de Onis, M.; Ezzati, M.; Mathers, C. and Rivera, J. for the Maternal and Child Undernutrition Study Group (2008) 'Maternal and Child Undernutrition: Global and

Regional Exposures and Health

Consequences', Lancet 37 1: 243-6

Bryce, J.; Coitinho, D.; Darnton-Hill, I.; Pelletier, D. and Pinstrup-Andersen, P. for the Maternal and Child Undernutrition Study Group (2008) 'Maternal and Child Undernutrition:
2 The use of the recommendations of the Task Force on Under Twos to portray the status of the inputs for reducing undernutrition is indicative, rather than prescriptive. The Task Force was convened in early 2008 and the report was published in September 2008 (Coalition for Sustainable Nutrition Security of India 2008). The Task Force recommendations are comparable to and inclusive of the recommendations of the Lancet Nutrition Series and those of the Working Group on Children Under Six (Working Group on Children Under Six, 2007).

Effective Action at National Level', Lancet, published online 17 January 2008, http://dx.doi.org/ 10.1016/S0140-6736(08)60250-0 (accessed 15 May 2009)

Coalition for Sustainable Nutrition Security of India (2008) Essential Interventions for Reducing Malnutrition in Infants and Young Children: A Leadership Agenda for Action for Nutrition, $1 \mathrm{st}$ edn, 19 September, New Delhi: Coalition for Sustainable Nutrition Security of India Deaton, A. and Drèze, J. (2009) 'Food and Nutrition in India: Facts and Interpretations', Economic and Political Weekly xliv.7, 14 February

Dubowitz, T.; Levinson, D.; Peterman, J.N.; Verma, G.; Jacob, S. and Schultink, W. (2007) 'Intensifying Efforts to Reduce Child Malnutrition in India: An Evaluation of the Dular Program in Jharkhand, India', Food Nutrition Bulletin 28.3: 266-73

Engle, P.L.; Menon, P. and Haddad, L.H. (1999)

'Care and Nutrition: Concepts and

Measurement', World Development 27.8: 1309-37

Gragnolati, M.; Shekar, M.; Das Gupta, M.; Bredenkamp, C. and Yi-Kyoung Lee (2005) India's Undernourished Children: A Call for Reform and Action, Health, Nutrition and Population (HNP) Discussion Paper, Washington DC: World Bank

Government of India, Ministry of Women and Child Development (2006a) Implementation Completion Report of World Bank Assisted ICDS-III (Women and Child Development) Project - Borrower's (Government of India) Evaluation Report, www.wcd.nic.in/PBEvalReport.pdf (accessed 5 February 2009) 
Government of India, Ministry of Women and Child Development, Central Project Management Unit (2007) ICDS-IV Project Revised Project Concept Note, http://motherchildnutrition.org/india/pdf/ mcn-icds4-project-concept-note.pdf (accessed 5 February 2009)

Harriss-White, B. (2004) 'Nutrition and its Politics in Tamil Nadu', South Asia Research 1: 51-71

Heaver, R. (2002) India's Tamil Nadu Nutrition Program: Lessons and Issues in Management and Capacity Building, HNP Discussion Paper, Health, Nutrition and Population, November, Washington DC: World Bank

International Institute for Population Sciences (IIPS) and ORC Macro (2007) National Family Health Survey (NFHS-3), 2005-06, India, 1, Mumbai: IIPS

Kingdon, J. (1995) Agendas, Alternatives and Public Policies, 2nd edn., New York: HarperCollins College

Menon, P.; Deolalikar, A. and Bhaskar, A. (2008a) The India State Hunger Index: Comparisons of Hunger Across 17 States in India, Washington DC: International Food Policy Research Institute (IFPRI)

Menon, P.; Mbuya, M.; Habicht, J.P.; Pelto, G.; Loechl, C.U. and Ruel, M.T. (2008b) 'Assessing Supervisory and Motivational Factors in the Context of a Program Evaluation in Rural Haiti', Journal of Nutrition 138: 634-7

Menon, P.; Pelletier, D.L.; Frongillo, E.A.; Stoltzfus, R.J.; Ahmed, T. and Ahmed, S. (under review) 'An Assessment Framework and Approach for Enabling Effective, Appropriate, and Feasible Policy and Program Choices and Actions: The Case of Undernutrition', submitted to the Bulletin of the World Health Organization

Mourad, M.M.; Arimond, M.; Dewey, K.G.; Trèche, S.; Ruel, M.T. and Delpeuch, F. (2008) 'Dietary Diversity is a Good Predictor of the Micronutrient Density of the Diet of 6- to 23month-old Children in Madagascar', Journal of Nutrition 138.2: 2448-53

Nair, K.R.G. (2007) 'Malnourishment Among Children in India: A Regional Analysis', Economic and Political Weekly, 15 September

Pelletier, D.L. (2001) 'Research and Policy Directions', in R. Semba and M. Bloem (eds), Nutrition and Health in Developing Countries, Totowa, NJ: Humana Press
Rajivan, A.K. (2006) 'Tamil Nadu: ICDS with a Difference', Economic and Political Weekly, 26 August: 3684-8

Right to Food Campaign (2008) Integrated Child Development Services Scheme: Presenting Innovative Panorama, New Delhi, www.righttofoodindia.org/ data/ICDS_presenting_innovative_panaromainternational_journal_of_development_econo mics.pdf (accessed 5 February 2009)

Seshadri, S.R. (2003) 'Constraints to Scaling-up Health Programs: A Comparative Study of Two Indian States', Journal of International Development 15.1: 101-14

Shiffman, J. (2007) 'Generating Political Priority for Maternal Mortality Reduction in 5 Developing Countries', American Journal of Public Health 97.5: 796-803

Shiffman, J. and Smith, S. (2007) Generation of Political Priority for Global Health Initiatives: A Framework and Case Study of Maternal Mortality', Lancet 370: 1370-9

Smith, L.C.; Ramakrishnan, U.; Ndiaye, A.; Haddad, L. and Martorell, R. (2003) The Importance of Women's Status for Child Nutrition in Developing Countries, Research Report 131, Washington DC: IFPRI

Sridhar, D. (2008) 'Hungry for Change: The World Bank in India', South Asia Research 28.2: 147-68

Supreme Court Commissioners (2007) Seventh Report of the Commissioners of the Supreme Court in the Case: PUCL v. UOI \& Ors. Writ Petition (Civil) No. 196 of 2001, November, 2007, New Delhi, India. Commissioners of the Supreme Court. www.sccommissioners.org/pdfs/comreports/ 7threport.pdf (accessed 15 May 2009)

UNICEF (United Nations Children's Fund) (1990) Strategy for Improved Nutrition of Children and Women in Developing Countries, UNICEF Policy Review Paper, New York: UNICEF

Von Braun, J.; Ruel, M.T. and Gulati, A. (2008) Accelerating Progress Toward Reducing Child Malnutrition in India: A Concept Note for Action, Washington DC: IFPRI

Working Group on Children Under Six (2007) 'Strategies for Children Under Six', Economic and Political Weekly, 29 December: 87-101

World Bank (2006) Repositioning Nutrition as Central to Development: A Strategy for Large-Scale Action, Washington DC: World Bank

WHO (2008) 'Indicators for Assessing Infant and Young Child Feeding Practices. Part 1, Definitions', conclusions of a consensus meeting held 6-8 November 2007 in Washington DC, USA: World Health Organization 